\title{
SISTEM KONTROL PEMANAS AIR MENGGUNAKAN SENSOR ULTRASONIK DAN ARDUINO UNO
}

\author{
Shafira Afra ${ }^{1}$,Nur Wahyudin ${ }^{2}$, Reza Vahlevi $^{3}$,Hendry Prayoga ${ }^{4}$,Novian ${ }^{5}$ \\ Jurusan Teknik Elektronika, Politeknik Negeri, Balikpapan \\ ${ }^{1}$ Jln. Soekarno Hatta KM.8,Batu Ampar, Kota Balikpapan, 76129, Indonesia \\ email:1 shafiraafra9@gmail.com ${ }^{2}$ muhammadrezavahlefi79@gmail.com 3ㅡwwhydn18@gmail.com \\ muhammadrezavahlefi79@gmail.com, ${ }^{4}$ hendryganteng66@gmail.com ${ }^{5}$ noviandwiprasetyo11@gmail.com
}

\begin{abstract}
A water heater control system is a device used to control water temperature by utilizing a heating element to heat water. By using a water heater control system, the heating element will activate when the water temperature is below the desired temperature and the heating element will automatically turn off when the temperature is above the desired temperature. To measure temperature in water, using a temperature sensor that is thermally sensitive resistor or commonly called thermocouple. The thermocouple resistance value will change with temperature changes. By using the principle of voltage divider, the voltage value will be input to Arduino and processed into temperature. To realize the water heating control system, a thermistor is needed as a
\end{abstract} temperature sensor, Arduino as an input processor, heating element as an actuator, and an LCD to display the temperature of the water. In addition, it is needed. [5]

Relay that functions as an electrical switch, in controlling the water conditions contained in a box that is equipped with an ultrasonic sensor as a prediction of the distance of the water that has been programmed. So that water can flow automatically with a distance controller that has been determined, if the distance of the water with ultrasonic. To be able to see it requires a valve / or drain plug that can move to the right or left. To drive the valve using a DC motor as a drive, with a type of DC servo motor. Because the DC motor uses direct current that requires a voltage of 4-6 Volt DC, because DC servo motors only move the valve which is small in shape. DC servo motor is a motor that is able to work both ways (CW and $\mathrm{CCW}$ ) with deflection of each angle reaching 90 ${ }^{\circ}$ so that the total deflection angle from right - center - left is $180^{\circ}$. The magnetic field of a DC servo motor is generated by a permanent magnet of a servo motor, so there is no need for power to create a magnetic field Servo motor will work well if the control pin is given with a frequency of $50 \mathrm{~Hz}$. Where when the signal with a frequency of $50 \mathrm{~Hz}$ is achieved at $1.5 \mathrm{~ms}$ Ton duty cycle conditions, the rotor of the motor will stop right in the middle $\left(0^{\circ} /\right.$ neutral angle $)$. When the Ton duty cycle of a given signal is less than $1.5 \mathrm{~ms}$, the rotor will rotate to the left by forming an angle that is linear in magnitude of the Ton duty cycle, and will survive in that position.[6]

\section{Keywords - Arduino UNO, LCD, Thermocouple, Water Temperature, Rela, Motor Servo.}

Abstrak -- Sistem kendali pemanas air adalah alat yang digunakan untuk mengendalikan suhu air dengan memanfaatkan element pemanas untuk memanaskan air. Dengan menggunakan sistem kendali pemanas air,element pemanas akan aktif bila suhu air berada di bawah suhu yang diinginkan dan element pemanas akan mati secara otomatis bila suhu berada di atas suhu yang diinginkan. Untuk mengukur suhu pada air, dengan menggunakan sensor suhu yaitu thermally sensitive resistor atau biasa disebut dengan thermocouple. Nilai resistansi thermocouple akan berubah seiring dengan perubahan suhu. Dengan menggunakan prinsip pembagi tegangan, nilai tegangan akan menjadi input pada arduino dan diolah menjadi suhu. Untuk merealisasikan sistem kendali pemanas air, dibutuhkan thermistor sebagai sensor suhu, arduino sebagai pemroses input, heating element sebagai actuator, dan LCD untuk menampilkan suhu pada air. Selain itu, dibutuhkan .[5]

Relay yang berfungsi sebagai saklar eletris, Dalam mengontrol kondisi air yang terdapat pada sebuah box yang di lengkapi dengan sensor ultrasonic yang sebagai prediksi jarak air yang telah di program. Agar air dapat mengalir secara otomatis dengan pengontrol jarak yang telah di tentukan,jika jarak air dengan ultrasonic. Untuk dapat melihatnya dibutuhkan valve/atau penutup saluran yang bisa bergerak kekanan atau kekiri. Untuk menggerakkan valve tersebut menggunakan motor DC sebagai penggerak, dengan jenis DC motor servo. Karena pada motor DC menggunakan arus searah yang membutuhkan tegangan 4-6 Volt DC, sebab DC motor servo hanya menggerakkan valve yang bentuknya kecil. DC motor servo adalah motor yang mampu bekerja dua arah $(\mathrm{CW}$ dan $\mathrm{CCW}$ ) dengan defleksi masing-masing sudut mencapai $90^{\circ}$ sehingga total defleksi sudut dari kanan - tengah -kiri adalah $180^{\circ}$. Medan magnit pada motor DC servo dibangkitkan oleh magnit permanent Motor servo, jadi tidak perlu tenaga untuk membuat medan magnet.

Motor Servo akan bekerja secara baik jika pada bagian pin kontrolnya diberikan dengan frekuensi $50 \mathrm{~Hz}$. Dimana pada saat sinyal dengan frekuensi $50 \mathrm{~Hz}$ tersebut dicapai pada kondisi Ton duty cycle $1.5 \mathrm{~ms}$, maka rotor dari motor akan berhenti tepat di tengah-tengah (sudut $0^{\circ} /$ netral). Pada saat Ton duty cycle dari sinyal yang diberikan kurang dari $1.5 \mathrm{~ms}$, maka rotor akan berputar ke arah kiri dengan membentuk sudut yang besarnya linier terhadap besarnya Ton duty cycle, dan akan bertahan diposisi tersebut. [6]

Kata Kunci-Arduino UNO, LCD, Thermocouple, Suhu Air, Relay, Motor Servo

\section{PENDAHULUAN}

Air adalah kebutuhan sehari hari kita yang kita gunakan untuk berbagai macam kegiatan yang menggunakan air. Air juga tidak hanya untuk mandi pada umumya, tetapi digunakan juga sebagai kebutuhan untuk memenuhi cairan dalam tubuh. Air yang diperlukan tubuh manusia juga berbeda, terkadang tubuh membutuhkan air yang hangat, sedang dan dingin tergantung cuaca dan keinginan kita.

Ketika kita ingin membuat suatu air yang hangat dan menyeseuaikan seberapa suhu yang diinginkan untuk air tersebut maka suhu akan terus bertambah hingga mendidih, sehingga suhu yang kita inginkan tidak mencapai sesuai 


\section{e-ISSN : 2715-5064}

seberapa suhu tersebut diinginkan. Maka alat ini akan menyesuaikan seberapa suhu yang kita inginkan tdak lebih dan tidak kurang.

Air juga membutuhkan sebuah wadah untuk menampung cairannya. Dimana air akan mengikuti bentuk wadah dari tempat yang tinggi ke tempat yang lebih rendah. Air akan mengalir ke wadah yang lain ketika ada celah pada wadah yang telah tersambung pipa kecil sebagai jembatannya yang di control manual (kran).

Arduino Uno sebagai mikrokontroller banyak dipakai sebagai sebagai sistem kontrol maupun sistem monitoring sebagai informasi.

\section{PENELITIAN YANG TERKAIT}

Penelitian yang terkait dalam praktikum ini adalah penggunaan motor servo sebagai penggerak CCTV untuk memonitoring kondisi pasien di ruang ICU.

Motor servo adalah sebuah aktuator putar (motor) yang bersifat closed feedback (umpan balik tertutup). Motor servo terdiri dari beberapa komponen seperti motor, potensiometer, rangkaian kontrol dan serangkaian gear. Potensiometer berfungsi sebagai penentu batas sudut dari berputarnya motor servo. Sedangkan untuk sudut dari motor servo diatur berdasarkan dari lebar pulsa yang dikirim memelalui kabel sinyal dari motor servo. Internal Gear berfungsi sebagai pengendali dari pergerakan dan sudut angularnya motor servo. Misalnya dengan pulsa $1.5 \mathrm{mS}$ pada periode selebar $2 \mathrm{mS}$ maka sudut dari sumbu motor akan berada pada posisi tengah. Semakin lebar pulsa OFF maka akan semakin besar gerakan sumbu ke arah jarum jam dan semakin kecil pulsa OFF maka akan semakin besar gerakan sumbu ke arah yang berlawanan dengan jarum jam.

Motor servo adalah motor yang berputar lambat, dimana biasanya ditunjukkan oleh rate putarannya yang lambat, namun demikian memiliki torsi yang kuat karena internal gearnya. Lebih dalam dapat digambarkan bahwa sebuah motor servo memiliki :

- $3 \mathrm{kabel}$; power(+5VDC), ground(-), dan control(data)

- Sinyal control berfungsi mengendalikan gerakan servo

- Operasional dari servo motor dikendalikan oleh sebuah pulsa selebar $\pm 20 \mathrm{~ms}$, dimana lebar pulsa antara $0.5 \mathrm{~ms}$ dan 2 ms menyatakan akhir dari range sudut maksimum.

- Konstruksi didalamnya meliputi internal gear, potensiometer, dan feedback control.

Relay merupakan suatu komponen (rangkaian) elektronika yang bersifat elektronis dan sederhana serta tersusun. PEMANFAATAN MOTOR SERVO SEBAGAI PENGGERAK CCTV. Blok Diagram Sistem Personal Computer (PC) Personal Computer (PC) berfungsi sebagai input data yang dimasukkan melalui komputer agar bisa dieksekusi oleh IC Max 232 menuju ke mikrokontroler AT mega 16, sehingga bisa menggerakkan motor servo sesuai perintah masukan data dari PC. Kabel RS 232 Kabel serial RS232 yang digunakan sebagai penghubung periferal dengan komputer pribadi. RS-232 adalah standar komunikasi serial RS-232 merupakan hal yang penting dalam sistem embedded, karena dengan komunikasi serial kita dapat dengan mudah menghubungkan mikrokontroler dengan devais lainnya. Port serial pada mikrokontroler terdiri atas dua pin yaitu RXD dan TXD, RXD berfungsi untuk menerima data dari komputer/perangkat lainnya, TXD berfungsi untuk mengirim data ke komputer/perangkat lainnya. Clear to Send Pin 5 (DB25), Pin 8 (DB9), CTS digunakan untuk mengeluarkan jawaban kepada isyarat RTS bila modem/piranti lain sedia untuk menerima data. CTS dikawal oleh modem/piranti lain dan dibaca oleh computer. IC Max 232 berfungsi sebagai rangkaian converter yaitu untuk menyesuaikan antara standar tegangan pada RS 232 dan standar pada pin-pin mikrokontroler. [7]

\section{PENJELASAN ALAT-ALAT}

\section{A. Komponen- Komponen}

\section{ARDUINO Uno}

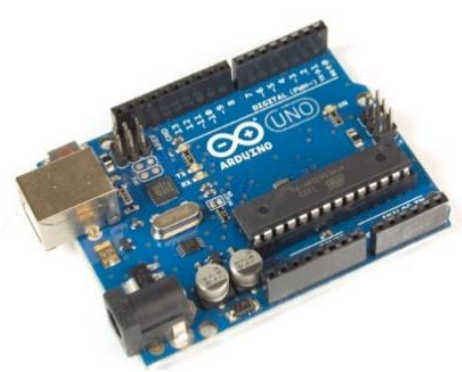

Gambar 3.1

Mikrokontroler Arduino, merupakan komponen utama dalam system yang di bangun berfungsi sebagai pusat pengendali berbagai macam peripheral yang terhubung pada komponen, yaitu motor servo, LCD, heater, sensor suhu (Thermocouple) dan sensor Ultrasonik.

\section{THERMOCOUPLE}

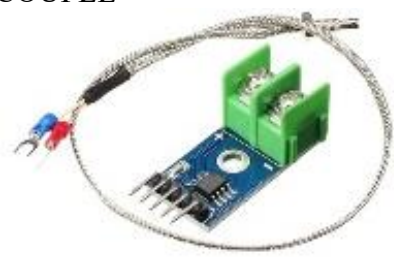

Gambar 3.2

Thermocouple ini adalah sensor suhu untuk mendeteksi suhu air yang telah di panaskan oleh heater dan dialiri melalui kran dengan suhu yang telah ditentukan oleh keinginan seseorang yang mendendalikan seberapa suhu yang diinginkan.

3. Relay

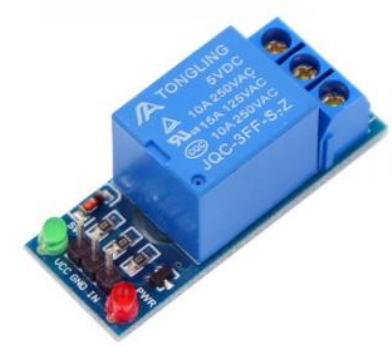

Gambar 3.3

Relay adalah sebuah komponen elektronika yang memiliki fungsi untuk menyambungkan dan memutuskan arus listrik di dalam sebuah rangkaian, jadi relay juga bisa disebut sebagai saklar otomatis. Relay menggunakan prinsip 


\section{e-ISSN : 2715-5064}

elektromagnetik apabila lilitan kawat pada inti besi teraliri arus listrik, maka relay akan terhubung dan pada saat arus listrik nya hilang atau dihentikan maka relay akan kembali seperti semula (tidak terhubung)

\section{Motor servo}

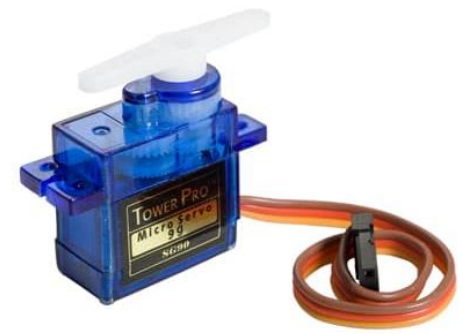

Gambar 3.4

Motor servo adalah sebuah aktuator putar (motor) yang bersifat closed feedback (umpan balik tertutup). Motor servo terdiri dari beberapa komponen seperti motor, potensiometer, rangkaian kontrol dan serangkaian gear. Potensiometer berfungsi sebagai penentu batas sudut dari berputarnya motor servo. Sedangkan untuk sudut dari motor servo diatur berdasarkan dari lebar pulsa yang dikirim memelalui kabel sinyal dari motor servo. Internal Gear berfungsi sebagai pengendali dari pergerakan dan sudut angularnya motor servo.

\section{Sensor Ultrasonik}

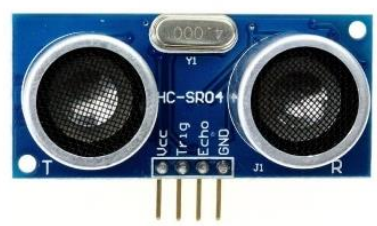

Gambar 3.5

Sensor ultrasonik adalah sebuah sensor yang memiliki fungsi mengubah bunyi menjadi besaran listrik dan begitupun sebaliknya. Cara kerja sensor ini mendeteksi sebuah objek yang berada didepannya dengan suara, suara tersebut dikirimkan oleh trasnmitter (Pemancar) dan apabila ada sebuah objek didepannya maka suara tadi akan dipantulkan dan kembali diterima oleh receiver (Penerima).

\section{Heater}

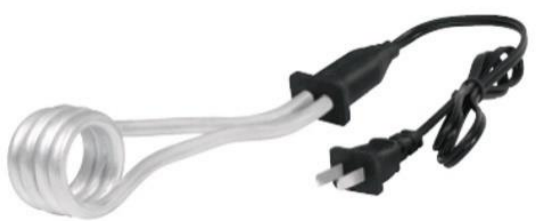

Gambar 3.6

Elemen Panas Listrik (Electrical Heating Element) pada water heater yaitu sebuah alat elektrik yang dapat memanaskan air dengan mudah dan dalam waktu yang singkat. Sumber panas elemen itu didapatkan dari kawat yang mempunyai tahan listrik tinggi (Resistance Wire), itulah mengapa kawat ini tidak meleleh ataupun terbakar saat heater memanas. Niklin yaitu bahan yang umum digunakan pada elemen, lalu di lapisi oleh bahan isolasi yang bisa melanjutkan panas, jadi aman untuk dipakai

\section{LCD displat $16 \times 2$}

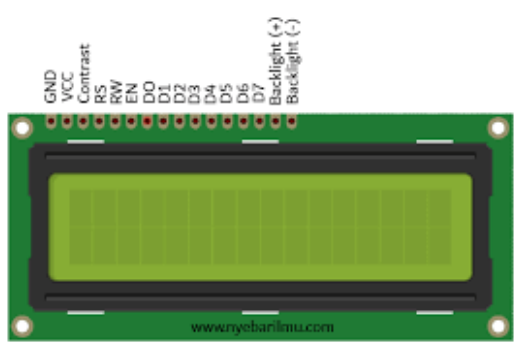

Gambar 3.7

LCD (Liquid Crystal Display) adalah suatu jenis media display (tampilan) yang menggunakan kristal cair (liquid crystal) untuk menghasilkan gambar yang terlihat. Dan LCD juga dapat menampilkan sebuah karakter pada layar LCD dengan menambahkan beberapa rangkaian tambahan.

\section{B. Gambar Rangkaian dan Flowchart}

Pada penjelasakn kali ini kami akan membahas tentang keterangan yang terdapat pada komponen yang kami rangkai,agar lebih mengetahui bagaimana tiap komponen bekerja semestinya. Untuk memperoleh hasil dalam implementasi ini di buat rangkaian seperti pada gambar :

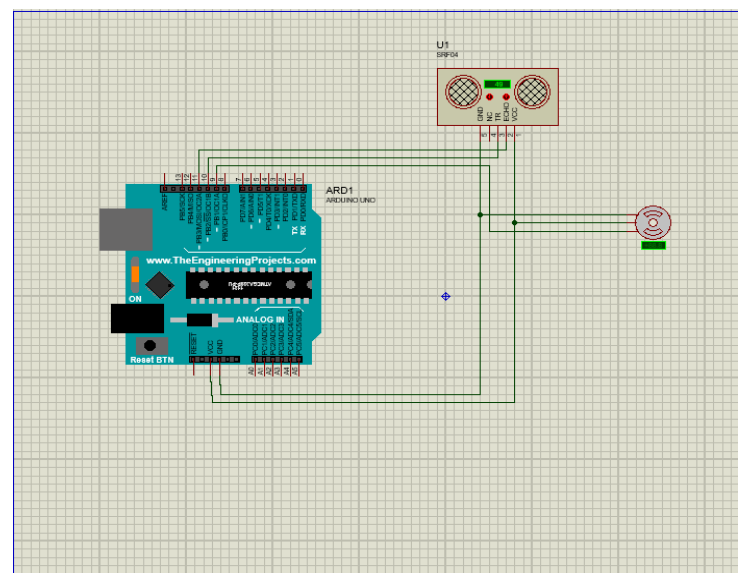

Gambar. 1.1 rangkaian proteus motor servo

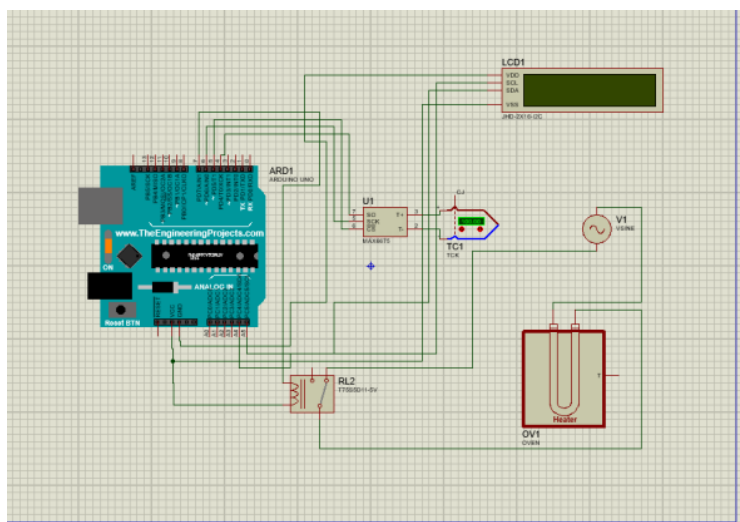

Gambar 1.2 rangkaian proteus Thermocouple 


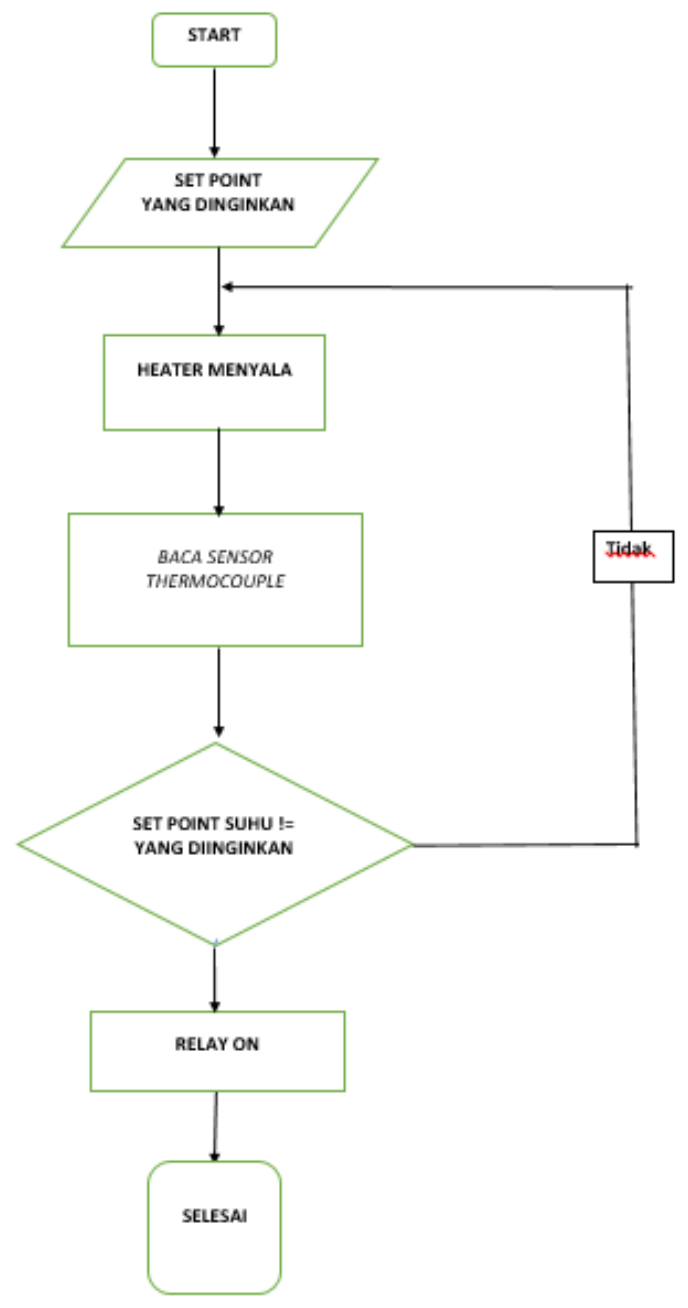

Gambar 2.1 flowchart sensor Thermocouple

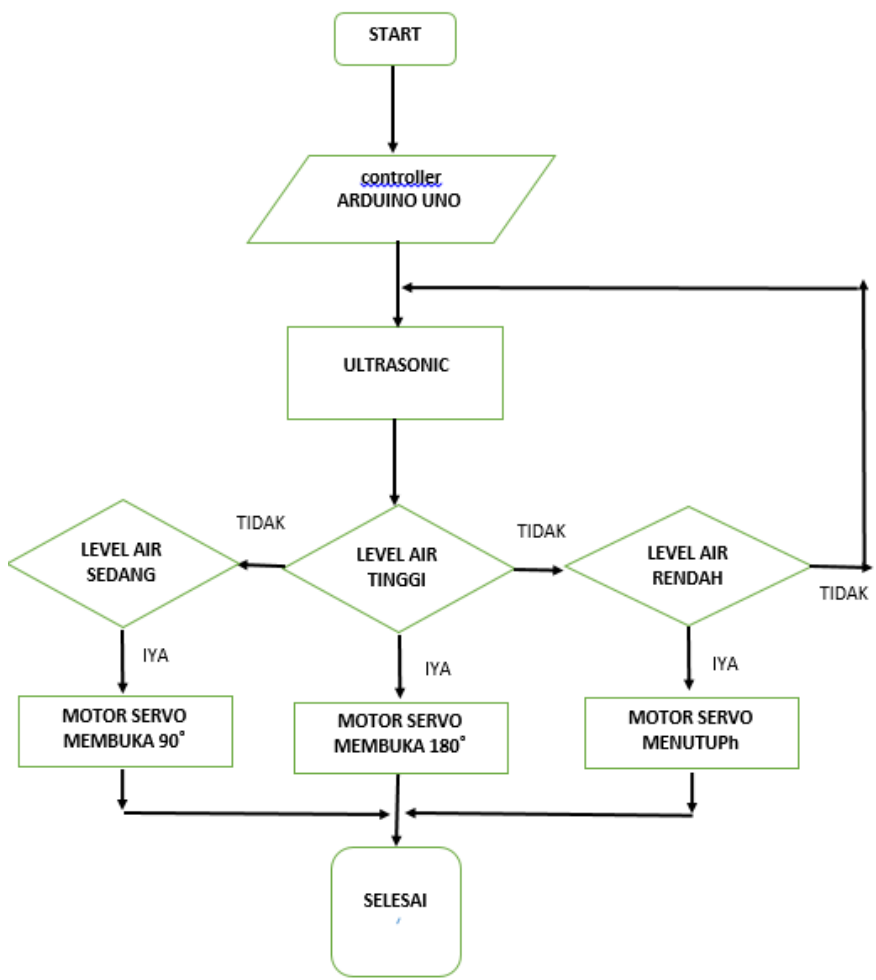

Gambar 2.2 FlowchartSensor Ultrasonik

\section{HASIL DAN PEMBAHASAN}

a. Rangkaian Alat

Dalam pengendalian suhu air ini, didukung dengan sebuah simulator system pendeteksi ketinggian air yang di tamping dengan keluaran melalui pipa kemudian air akan dipanaskan dengan heater dengan suhu yang telah ditentukan. Thermocouple akan mendeteksi suhu yang terdapat pada air tersebut dan ditampilkan melalui LCD Display.

Gambar 4.1 Rangkaian alat

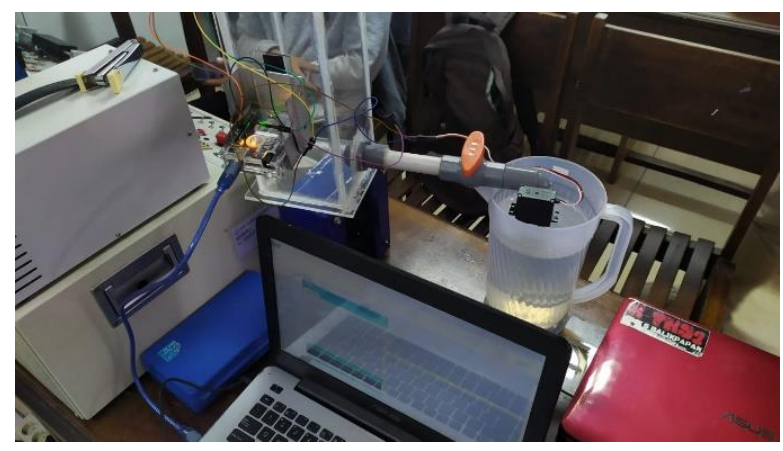

b. Hasil Pengukuran Waktu Suhu Panas

TABEL

BATASAN SUHU YANG DICAPAI

\begin{tabular}{|c|c|}
\hline SUHU & WAKTU \\
\hline $40-50^{0}$ & $5 \mathrm{~m}: 32 \mathrm{~s}$ \\
\hline $51-60^{0}$ & $7 \mathrm{~m}: 28 \mathrm{~s}$ \\
\hline $61-70^{0}$ & $8 \mathrm{~m}: 49 \mathrm{~s}$ \\
\hline $71-80^{0}$ & $10 \mathrm{~m}: 11 \mathrm{~s}$ \\
\hline $81-90^{0}$ & $11 \mathrm{~m}: 34 \mathrm{~s}$ \\
\hline $91-100^{0}$ & $13 \mathrm{~m}: 50 \mathrm{~s}$ \\
\hline
\end{tabular}


Table 4.1

System kendali suhu air dan ketinggian air oleh sensor thermocouple dan ultrasonik dalam simulator proses pemanasan air dengan batas yang telah di tentukan dapat membantu manusia dalam memanaskan air dengan suhu yang tidak terlalu panas maka air yang telah di panaskan bisa langsung digunakan, karena air tidak terlalu mendidih (mencapai suhu maksimum air) yang dapat merusak objek tersebut. Pada alat ini dapat memanaskan air hingga $100^{\circ} \mathrm{C}$ dngan kurun waktu yang cepat,sehingga mempermudah dalam memenaskan air yang akan segera digunakan. Kendali ini dilakukan dengan pemanfaatkan tegangan yang dihasilkan dari sensor thermocouple akibat adanya perbedaan suhu yang terjadi antara titik hot junction. Penggunaan sensor ultrasonic digunakan juga untuk mendeteksi ketinngian air sehingga air tidak overload dan akan terbuang sia-sia. Berhubung dalam penelitian ini hanya berupa simulator, maka suhu maximal yang diukur hanya mencapai $100^{\circ} \mathrm{C}$.

c. Hasil Pengujian Keakurasian Jarak sensor

TABEL II

HASIL PENGUKURAN JARAK

\begin{tabular}{|c|c|c|}
\hline NO & JARAK $(\mathrm{cm})$ & $\begin{array}{c}\text { TERUKUR } \\
\text { SENSOR }\end{array}$ \\
\hline 1 & 2 & 2 \\
\hline 2 & 4 & 4 \\
\hline 3 & 6 & 6 \\
\hline 4 & 8 & 8 \\
\hline 5 & 10 & 10 \\
\hline 6 & 12 & 12 \\
\hline 7 & 14 & 14 \\
\hline 8 & 16 & 15 \\
\hline 9 & 18 & 17 \\
\hline 10 & 20 & 19 \\
\hline
\end{tabular}

Table 4.2

Dari table diatas yang merupakan perandingan antara jarak sebenarnya dengan jarak yang teukur pada sensor yang menunjukkan nilai yang tidak jauh berbeda dan masih mendekati dengan jarak sebenarnya.

d. Hasil Pergerakan Pada Motor Servo

TABEL III

HASIL PENGUKURAN MOTOR

\begin{tabular}{|c|c|c|}
\hline NO & $\begin{array}{c}\text { JARAK } \\
\text { KETINGIAN AIR } \\
\text { (CM) }\end{array}$ & $\begin{array}{c}\text { PUTARAN } \\
\text { MOTOR } \\
\text { SERVO }\end{array}$ \\
\hline 1 & 20 & $18^{0}$ \\
\hline 2 & 18 & $36^{0}$ \\
\hline 3 & 16 & $54^{0}$ \\
\hline 4 & 14 & $72^{0}$ \\
\hline 5 & 12 & $90^{0}$ \\
\hline 6 & 10 & $108^{0}$ \\
\hline 7 & 8 & $126^{0}$ \\
\hline 8 & 6 & $144^{0}$ \\
\hline 9 & 4 & $162^{0}$ \\
\hline 10 & 2 & $180^{0}$ \\
\hline
\end{tabular}

Table 4.3

Jadi jika jarak ketinggian air semakin mendekati sensor maka valve yang di gerakkan oleh motor servo akan membuka sebesar $180^{\circ}$. Semakin jarak air mendekati sensor air
Hasil Dalam Pergerakan Semua Komponen

TABEL IV

HASIL KETIKA ALAT DI AKTIFKAN

\begin{tabular}{|c|l|l|c|c|}
\hline NO & SUHU & TIME & $\begin{array}{c}\text { JARAK } \\
\text { AIR }\end{array}$ & $\begin{array}{c}\text { PUTARAN } \\
\text { MOTOR } \\
\text { SERVO }\end{array}$ \\
\hline 1 & $40-50^{0}$ & $5 \mathrm{~m}: 32 \mathrm{~s}$ & 2 & $162-180^{0}$ \\
\hline 2 & $51-60^{0}$ & $7 \mathrm{~m}: 28 \mathrm{~s}$ & 6 & $144-162^{0}$ \\
\hline 3 & $61-70^{0}$ & $8 \mathrm{~m}: 49 \mathrm{~s}$ & 10 & $108-126^{0}$ \\
\hline 4 & $71-80^{0}$ & $10 \mathrm{~m}: 11 \mathrm{~s}$ & 14 & $90-108^{0}$ \\
\hline 5 & $81-90^{0}$ & $11 \mathrm{~m}: 34 \mathrm{~s}$ & 16 & $54-72^{0}$ \\
\hline 6 & $91-100$ & $13 \mathrm{~m}: 50 \mathrm{~s}$ & 20 & $18-0^{0}$ \\
\hline
\end{tabular}

Table 4.4

Dari table ini merupakan ringkasan dari keseluruhan ketika alat diaktifkan secara bersaman. Suhu dapat diperkirakan dengan waktu yang telah terlewati seperti pada table diatas, dan kita dapat mengetahui seberapa besar putaran motor servo akan membuka hingga menutup valve tersebut.

\section{KESIMPULAN}

Pada praktikum ini kami dapat menyimpulkan bahwa:

1. Relay akan berfungsi sebagaimana mestinya pada rangkaian $\mathrm{NC}$ dan $\mathrm{NO}$

2. Tampilan pada LCD akan menampilkan berapa suhu air yang telah di proses yang telah diatur dalam Arduino

3. Thermocouple yang bekerja untuk mendeteksi suhu yang terdapat pada air yang akan di teruskan ke relay untuk memutuskan jalur karena telah mencapai suhu yang diinginkan.

4. Sensor ultrasonic mendeteksi jarak air yang akan mengendalikan relay open atau close secara automatia.

5. Motor servo, bekerja sesuai dengan jarak yang di deteksi oleh sensor ultrasonik

\section{UCAPAN TERIMA KASIH}

Pada bab ini kami akan menyampaikan kepada dosen kami, dan para anggota kelompok kami serta sumber referensireferensi yang kami kutip yang telah membantu dalam menyelesaikan projek lat ini. Jika ada perkataan yang tidak tepat atau kurang kami mohon maaf sebesar-besarnya, dan jika ada saran kami siap untuk menerima saran yang di berikan. Terimaksih

\section{DAFTAR PUSTAKA}

[1] Bashori, Z., Sumardi, \& Setiawan, I. (2013). Pengendalian Temperatur pada Plant Sederhana Electric Furnace Berbasis Sensor Thermocouple dengan Metode Kontrol PID. Jurnal Teknik Elektro, 2, 1-8.A. K.

[2] Huda, S. N. (2011). Rancang Bangun Sistem Pengendali Temperatur Furnance Dengan Menggunakan Sensor Termokopel Tipe-K Berbasis Mikrokontroler ATMEGA 16. Depok

[3] Udin S. Winataputra.. Srategi Belajar mengajar. (Jakarta: Universitas Terbuka Departemen Pendidikan Nasional 2003).

[4] H. Santoso, Panduan Praktis Arduino Untuk Pemula. www.elangsakti.com, 2016 
e-ISSN : 2715-5064

[5] Wendri, N., Supardi, I. W., Suarbawa, K. N., \& Yuliantini, N. M. (2012). Alat Pencatat Temperatur Otomatis Menggunakan Termokopel Berbasis Mikrokontroler AT89S51. Buletin Fisika, 13(1), 29-33

[6] Datasheet,2013. Parallax: Ultrasonic distance sensor.volume 2 (9 pages).

[7] Ahmad Hilal, Saiful Manan. (2012 - 2013). Pemanfaatan motor servo sebagai penggerak cctv untuk alat monitoring dan kondisi pasien di ruang ICU, Jurnal Gema Teknologi, vol.17 no. 2. 